Revista Destaques Acadêmicos, Lajeado, v. 11, n. 3, 2019. ISSN 2176-3070

DOI: http://dx.doi.org/10.22410/issn.2176-3070.v11i3a2019.2116

http://www.univates.br/revistas

\title{
APLICAÇÃO DA TEORIA DO CUIDADO HUMANO EM UMA UNIDADE DE TERAPIA INTENSIVA: RELATO DE EXPERIÊNCIA DA ENFERMAGEM
}

\author{
Bruno do Nascimento Tavares ${ }^{1}$, Thamires de Sousa Cruz², Kerstym Santos ${ }^{3}$, \\ Vitória Schober Rocha Santos ${ }^{4}$, Joice Aparecida Sobral da Silva ${ }^{5}$, \\ Jacqueline Emanuelly Szalbot ${ }^{6}$, Roberta Marie Ogawa ${ }^{7}$, Luana Tonin ${ }^{8}$, \\ Fernanda de Oliveira Andrade ${ }^{9}$, Juliana Ollé Mendes da Silva ${ }^{10}$, \\ Karin Rosa Persegona Ogradowski ${ }^{11}$
}

\begin{abstract}
Resumo: O objetivo dessa pesquisa foi descrever a experiência de acadêmicos de enfermagem ao relacionar e aplicar os princípios da Teoria do Cuidado Humano de Jean Watson aos cuidados intensivos em uma Unidade de Terapia Intensiva adulto. Tratase de um relato de experiência, vivido por estudantes de graduação em Enfermagem, entre os meses de agosto a novembro de 2018 durante o ensino clínico de urgência e emergência. A partir dos diagnósticos elencados através doNANDA, foram identificados
\end{abstract}

1 Acadêmico de enfermagem. Faculdades Pequeno Príncipe. bnt.bruno@hotmail.com.

2 Acadêmica de enfermagem. Faculdades Pequeno Príncipe. tthami.290698@gmail.com.

3 Acadêmica de enfermagem. Faculdades Pequeno Príncipe. kerstyms@hotmail.com.

4 Acadêmica de enfermagem. Faculdades Pequeno Príncipe. vitoria_schober@outlook.com.

5 Acadêmica de enfermagem. Faculdades Pequeno Príncipe. joicetkr@hotmail.com.

6 Acadêmica de enfermagem. Faculdades Pequeno Príncipe. jaaq.looly@gmail.com.

7 Acadêmica de enfermagem. Faculdades Pequeno Príncipe. robertamarieogawa@gmail.com.

8 Professora da Faculdades Pequeno Príncipe. Doutorado em andamento pelo Programa de PósGraduação em Enfermagem da Universidade Federal do Paraná.luanatonin@hotmail.com.

9 Professora da Faculdades Pequeno Príncipe. Mestre em Ciências pela Escola de Enfermagem da Universidade de São Paulo. feroa1@hotmail.com.

10 Professora da Faculdades Pequeno Príncipe. Mestre no Ensino nas Ciências da Saúde pela Faculdades Pequeno Príncipe. juollesilva@gmail.com.

11 Coordenadora do curso de graduação em Enfermagem da Faculdades Pequeno Príncipe. Doutorado em andamento pelo Programa de Pós-Graduação em Biotecnologia Aplicada a Saúde da Criança e do Adolescente. karin.persegona@fpp.edu.br 
elementos do Processo Clinical Caritas para estabelecer o plano de cuidados e quais as ações o enfermeiro poderia desenvolver para o atendimento das necessidades. Concluise que o cuidado desenvolvido por intermédio da teoria em questão, proporciona ao enfermeiro ou ao futuro profissional, acolher, confortar, orientar, respeitar e ofertar ao paciente um cuidado digno e responsivo as suas necessidades de saúde.

Palavras-chave: Teoria de Enfermagem. Unidades de Terapia Intensiva. Educação em Enfermagem.

\section{INTRODUÇÃO}

Com o avanço tecnológico em todas os campos, principalmente nas áreas da educação e da saúde, as Instituições de Ensino Superior (IES), sobretudo da área da saúde encontram desafios para impactar a formação dos futuros profissionais e que estes sejam responsivos as necessidades da população (MELLO; ALVES; LEMOS, 2014).

Aliado a isto, as IES devem estar sempre em busca de atualizações e novas formas de instruir e cativar os alunos. Então como uma possível ferramenta pedagógica, a aplicação de metodologias ativas de aprendizagem instiga os alunos a buscarem conhecimento e relacioná-los com a prática que é de extrema importância para a construção da bagagem de experiências do futuro profissional (MELLO; ALVES; LEMOS, 2014).

No decurso da graduação de enfermagem os acadêmicos tiveram experiências diferenciadas de aprendizagem por meio do uso de metodologias ativas para a elaboração de trabalhos e seminários, com enfoque principal na metodologia da problematização que a partir da observação da realidade é elaborado hipóteses ou intervenções para alterar ou melhorar tal perspectiva (VIEIRA; PANÚNCIO-PINTO, 2015; OGRADOWSKI et al., 2018), entretanto, a construção do presente trabalho buscou realizar a sua intervenção com luz ao referencial teórico da Teoria do Cuidado Humano de Jean Watson (WATSON, 2012; TONIN et al., 2017).

Esta teoria pode ser aplicada para exercer um cuidado digno e completo ao paciente, visando à necessidade da aproximação do profissional da Enfermagem com os aspectos de humanidade e transcendência de cada ser humano, que ultrapassa o físico e o momento, deixando de observar o homem somente como um elemento biológico (MEDEIROS, 2017; RIEGEL, CROSSETTI, SIQUEIRA, 2018).

Desta forma, o cuidado é evidenciado e desenvolvido de forma transpessoal, no qual a percepção vai além da proporção física, é capaz de ultrapassar o momento e o cosmos (WATSON, 2012). Destarte, temos como a essência da Teoria do Cuidado Humano o cuidado transpessoal, o qual pode ser efetivado mediante a utilização dos elementos do Processo Clinical Caritas que possibilitam sua aplicação na prática. 
Assim, o Processo Clinical Caritas é composto por 10 elementos, citados a seguir: Praticar o amor-gentileza e a equanimidade, no contexto da consciência de cuidado; Ser autenticamente presente, fortalecendo, sustentando, honrando o profundo sistema de crenças e o mundo de vida subjetivo do ser cuidado; Cultivar práticas espirituais próprias e do eu transpessoal e ir além do próprio ego; Desenvolver e sustentar uma autêntica relação de cuidado, ajuda confiança; Ser presente e apoiar a expressão de sentimentos positivos e negativos como uma conexão profunda com o próprio espírito e o da pessoa cuidada; Usar criativamente o eu e todos os caminhos do conhecimento como parte do processo de cuidar, engajar-se em práticas artísticas de cuidado reconstituição (healing); Engajar-se de forma genuína em experiências de ensino aprendizagem que atendam a pessoa inteira, seus significados, tentando permanecer dentro do referencial do outro; Criar um ambiente de reconstituição (healing) em todos os níveis (físico e não-físico), ambiente sutil de energia e consciência, no qual a totalidade, beleza, conforto, dignidade e paz sejam potencializados; Ajudar nas necessidades básicas, com consciência intencional de cuidado, administrando "o cuidado humano essencial", que potencializa o alinhamento mente-corpoespírito, a totalidade e unidade do ser em todos os aspectos do cuidado; Dar abertura e atender aos mistérios espirituais e dimensões existenciais da vidamorte, cuidar da sua própria alma e da do ser cuidado (WATSON, 2019).

A situação-problema encontrada (observação da realidade) a partir da metodologia fora os cuidados realizados a um paciente com DPOC (Doença Pulmonar Obstrutiva Crônica) em cuidados paliativos internado em uma UTI (Unidade de Terapia Intensiva). A DPOC é uma patologia, tratável e de prevenção, caracterizada pela obstrução crônica do fluxo aéreo, porém sem prognóstico de cura, principalmente quando diagnosticada tardiamente (SEIXAS, RAMOS, RICARDO, 2016). Assim, o cuidado paliativo é uma abordagem que pode promover a qualidade de vida de pacientes e seus familiares, que enfrentam doenças que ameaçam a continuidade da vida, por meio da prevenção e alívio do sofrimento. Requer a identificação precoce, avaliação e tratamento da dor e outros problemas de natureza física, psicossocial e espiritual (OMS, 2015).

Em uma UTI é possível encontrar possíveis barreiras para a aplicação de uma linha de cuidados devido ao elevado grau de complexidade e situações urgentes que são recorrentes, ainda mais em pacientes que se encontram na terminalidade da vida e que possuem mais necessidades que outros (MACHADO; SOARES, 2016). Assim, o desenvolvimento de uma humanização da assistência pode iniciar-se a partir de uma elaboração de um plano de cuidados transpessoais, no presente estudo estes foram alicerçados no referencial teórico de Jean Watson (WATSON, 2012), e aplicados conforme proposto pelo "Guia para a realização dos Elementos do Processo Clinical Caritas" (TONIN et al., 2017). 
Considerando a experiência ímpar proporcionada por esta modalidade de cuidado transpessoal promissora e em ascensão que possibilita desenvolver cuidados humanizados em diferentes instituições de saúde e com diferentes populações (DURANT et al., 2015; SWENGROSS et al., 2014; ARSLANOZKAN; OKUMUS; BULDUKOGLU, 2013; TONIN et al., 2019), torna-se imprescindível que acadêmicos de enfermagem vivenciem esta experiência durante sua graduação (ACKERMAN, 2018).

Logo este manuscrito, tem como objetivo descrever a experiência de acadêmicos de enfermagem ao relacionar e aplicar os princípios da Teoria do Cuidado Humano de Jean Watson aos cuidados intensivos ao paciente adulto, criticamente enfermo.

\section{METODOLOGIA}

Trata-se de um relato de experiência, que permite narrar fatos a partir de experiências e vivências do investigador, advindos de situações do cotidiano. Segundo Dyniewicz (2009) tal metodologia apresenta as motivações para as ações tomadas na situação e as considerações/impressões que a vivência trouxe ao profissional. Inclui uma introdução com marco teórico, objetivos da vivência e expõe as etapas empregadas. Após isso, apresentam-se os resultados observados e as considerações tecidas a partir dos mesmos ${ }^{12}$.

Deve-se buscar aparatos teóricos para basear o reflexo que se busca atingir, já que o mesmo tem o intuito de contribuir para pesquisadores e profissionais da área que futuramente apresentem interesse ou necessidade de informações sobre o assunto ${ }^{11}$.

Assim, este relato foi construído a partir da experiência vivida por acadêmicos de Enfermagem do sexto período, de uma faculdade filantrópica, localizada na região sul do Brasil, durante seu estágio em Urgência e Emergência, entre os meses de agosto a novembro de 2018. O campo de atuação correspondeu a uma UTI de um hospital de porte médio localizado na região sul do Brasil.

Dentro do contexto observado procurou-se desenvolver maneiras de realizar da melhor forma possível a assistência de enfermagem baseada na Teoria do cuidado Humano de Jean Watson, englobando os elementos do Processo Clinical Caritas e as manifestações de cuidado possíveis de serem realizadas conforme proposto pela teórica em questão e o "Guia para a realização dos Elementos do Processo Clinical Caritas" (TONIN et al., 2017).

12 DYNIEWICZ, Ana Maria. Metodologia da pesquisa em saúde para iniciantes. 1.ed. São Paulo: Difusão, 2009. 


\section{RESULTADOS}

Após a vivência em campo, a partir da observação da realidade, foram levantados os problemas, e posteriormente estabelecidos diagnósticos de enfermagem segundo o North American Nursing Diagnosis Association (2017), para que então, baseado nos mesmos, fossem identificados os Elementos do Processo Clinical Caritas que pudessem ajudar a desenvolver e aplicar intervenções de enfermagem voltados para o Cuidado Humano, para assim alterar/melhorar a realidade existente até o presente momento.

Seguiu-se a proposta de elencar diagnósticos reais e potenciais para a situação evidenciada, dando assim a oportunidade de moldar os elementos independentemente da situação apresentada, e estimulando o senso crítico do profissional perante o seu ambiente de trabalho e maneiras de realizar a assistência. Partindo desse preceito, deu-se o seguinte quadro:

Quadro 1: Diagnósticos de enfermagem e intervenções segundo Elementos do Processo Clinical Caritas

\begin{tabular}{|c|c|c|}
\hline $\begin{array}{l}\text { Diagnósticos de } \\
\text { Enfermagem }\end{array}$ & $\begin{array}{l}\text { Elementos do Processo } \\
\text { Clinical Caritas }\end{array}$ & Manifestações de Cuidado \\
\hline $\begin{array}{l}\text { Conforto prejudicado, } \\
\text { relacionado ao controle } \\
\text { situacional evidente, } \\
\text { evidenciado pelo } \\
\text { descontentamento com } \\
\text { a situação. }\end{array}$ & $\begin{array}{l}\text { - Desenvolver e sustentar } \\
\text { uma autêntica relação de } \\
\text { cuidado, ajuda na confiança; } \\
\text { - Ser presente e apoiar a } \\
\text { expressão de sentimentos } \\
\text { positivos ou negativos como } \\
\text { uma conexão profunda com } \\
\text { o próprio espírito e o da } \\
\text { pessoa cuidada. }\end{array}$ & $\begin{array}{l}\text { - Colocar-se no lugar do outro; } \\
\text { - Cuidar de forma genuína, } \\
\text { confortar, acalmar, tocar; } \\
\text { - Dispor-se a estar presente no } \\
\text { momento do cuidado para explorar } \\
\text { todas as possibilidades; } \\
\text { - Estimular aceitação no momento. }\end{array}$ \\
\hline $\begin{array}{l}\text { Tensão do papel de } \\
\text { cuidador, caracterizado } \\
\text { por dificuldade na } \\
\text { aceitação da doença } \\
\text { e do tratamento } \\
\text { relacionado à doença } \\
\text { pulmonar obstrutiva } \\
\text { crônica e relação com o } \\
\text { medo da terminalidade } \\
\text { da vida. }\end{array}$ & $\begin{array}{l}\text { - Usar criativamente o eu } \\
\text { e todos os caminhos do } \\
\text { conhecimento como parte do } \\
\text { processo de cuidar, engajar- } \\
\text { se em práticas artísticas } \\
\text { de cuidado reconstituição } \\
\text { (healing). }\end{array}$ & $\begin{array}{l}\text { - Orientar o familiar sobre os } \\
\text { cuidados essenciais que deve ter; } \\
\text { - Encorajar o familiar a não } \\
\text { ter medo de assumir tamanha } \\
\text { responsabilidade; } \\
\text { - Prevenir sobre as possíveis } \\
\text { complicações acerca da patologia e } \\
\text { as condutas a serem tomadas. }\end{array}$ \\
\hline $\begin{array}{l}\text { Dor crônica, } \\
\text { caracterizado pelo } \\
\text { paciente não ter } \\
\text { capacidade de realizar } \\
\text { atividades prévias, } \\
\text { evidenciado pelas } \\
\text { condições físicas } \\
\text { apresentada pelo } \\
\text { paciente. }\end{array}$ & $\begin{array}{l}\text { - Desenvolver e sustentar } \\
\text { uma autêntica relação de } \\
\text { cuidado, ajuda na confiança; } \\
\text { - Ajudar nas necessidades } \\
\text { básicas, com consciência } \\
\text { internacional do cuidado } \\
\text { administrado "o cuidado } \\
\text { humano essencial", que } \\
\text { potencializa o alinhamento } \\
\text { mente-corpo-espirito, a } \\
\text { totalidade e unidade do } \\
\text { ser em todos os aspectos } \\
\text { cuidados. }\end{array}$ & $\begin{array}{l}\text {-Satisfazer as necessidades da } \\
\text { pessoa, identificada pelo profissional } \\
\text { e pelo próprio ser cuidado; } \\
\text { - Antecipar a necessidade do cliente; } \\
\text { - Compreender suas necessidades. }\end{array}$ \\
\hline
\end{tabular}




\begin{tabular}{|c|c|c|}
\hline $\begin{array}{l}\text { Diagnósticos de } \\
\text { Enfermagem }\end{array}$ & $\begin{array}{l}\text { Elementos do Processo } \\
\text { Clinical Caritas }\end{array}$ & Manifestações de Cuidado \\
\hline $\begin{array}{l}\text { Desempenho de papel } \\
\text { ineficaz, caracterizado } \\
\text { por adaptação } \\
\text { inadequada à } \\
\text { mudança, relacionado } \\
\text { por preparo ineficiente } \\
\text { para o papel de } \\
\text { cuidador. }\end{array}$ & $\begin{array}{l}\text { - Usar criativamente o eu } \\
\text { e todos os caminhos do } \\
\text { conhecimento como parte do } \\
\text { processo de cuidar, engajar- } \\
\text { se em práticas artísticas } \\
\text { de cuidado reconstituição } \\
\text { (healing). }\end{array}$ & $\begin{array}{l}\text { - Encorajar o familiar a desenvolver } \\
\text { um diário onde deve ser relatado } \\
\text { todas as dificuldades encontradas } \\
\text { pelo mesmo no cuidado diário com } \\
\text { o paciente. Relatar ao profissional } \\
\text { visando a necessidade de orientação; } \\
\text { - Orientar familiar sobre a } \\
\text { necessidade de compartilhar os } \\
\text { medos e anseios aos profissionais } \\
\text { revelando uma verdadeira troca de } \\
\text { experiências. }\end{array}$ \\
\hline $\begin{array}{l}\text { Risco de síndrome do } \\
\text { idoso frágil relacionado } \\
\text { a depressão, } \\
\text { evidenciado pela } \\
\text { tristeza apresentada } \\
\text { pelo paciente }\end{array}$ & $\begin{array}{l}\text { - Dar abertura e atender } \\
\text { aos mistérios espirituais e } \\
\text { dimensões existenciais da } \\
\text { vida-morte, cuidar da sua } \\
\text { própria alma e da do ser } \\
\text { cuidado. }\end{array}$ & $\begin{array}{l}\text { - Saber o que é importante para si e o } \\
\text { que tem significado para o outro; } \\
\text { - Estimular a busca de forças } \\
\text { internas para o cuidado; } \\
\text { - Reconhecer o processo de vida e } \\
\text { morte; } \\
\text { - Manter o espaço sagrado de cura } \\
\text { para os outros, respeitando o seu } \\
\text { tempo e a sua necessidade. }\end{array}$ \\
\hline $\begin{array}{l}\text { Processos familiares } \\
\text { disfuncionais, } \\
\text { caracterizado por } \\
\text { dificuldade de } \\
\text { interação entre familiar } \\
\text { cuidador e paciente } \\
\text { relacionado a mudança } \\
\text { da rotina do cuidador } \\
\text { e da responsabilidade } \\
\text { com a paciente } \\
\text { totalmente dependente. }\end{array}$ & $\begin{array}{l}\text { - Ajudar nas necessidades } \\
\text { básicas, com consciência } \\
\text { intencional de cuidado, } \\
\text { administrando o cuidado } \\
\text { humano essencial, que } \\
\text { potencializa o alinhamento } \\
\text { mente-corpo-espírito, a } \\
\text { totalidade e unidade do ser } \\
\text { em todos os aspectos do } \\
\text { cuidado. }\end{array}$ & $\begin{array}{l}\text { - Orientar o cuidador sobre os } \\
\text { cuidados essenciais que este deve } \\
\text { ter e encorajá-lo a não ter medo de } \\
\text { assumir tamanha responsabilidade; } \\
\text { - Promover o processo de adaptação } \\
\text { familiar as novas condiçôes, e } \\
\text { entender que haverá conflitos entre } \\
\text { os membros; } \\
\text { - Mostrar que a união do familiar } \\
\text { e paciente é de vital importância } \\
\text { para a qualidade de vida de todos } \\
\text { os envolvidos e que o medo do } \\
\text { desconhecido é normal, e pode ser } \\
\text { superado; } \\
\text { - Orientar o cuidador e a família, } \\
\text { explicando sobre a doença do } \\
\text { indivíduo, as mudanças que esta vai } \\
\text { causar na vida da família. }\end{array}$ \\
\hline $\begin{array}{l}\text { Ventilação espontânea } \\
\text { prejudicada } \\
\text { relacionado a doença } \\
\text { pulmonar obstrutiva } \\
\text { crônica evidenciado } \\
\text { por dificuldade } \\
\text { respiratória aparente. }\end{array}$ & $\begin{array}{l}\text { - Ajudar nas necessidades } \\
\text { básicas, com consciência } \\
\text { intencional de cuidado, } \\
\text { administrando "o cuidado } \\
\text { humano essencial", que } \\
\text { potencializa o alinhamento } \\
\text { mente-corpo-espírito, a } \\
\text { totalidade e unidade do ser } \\
\text { em todos os aspectos do } \\
\text { cuidado. }\end{array}$ & $\begin{array}{l}\text { - Compreender as necessidades do } \\
\text { cliente; } \\
\text { - Cuidar de forma genuína, } \\
\text { confortar, acalmar, tocar; } \\
\text { - Estimular métodos para melhora } \\
\text { da respiração. }\end{array}$ \\
\hline $\begin{array}{l}\text { Risco de integridade } \\
\text { da pele prejudicada } \\
\text { relacionado a } \\
\text { decúbito prolongado } \\
\text { evidenciado por } \\
\text { hiperemia em região } \\
\text { sacrococcígea. }\end{array}$ & $\begin{array}{l}\text { - Criar um ambiente de } \\
\text { reconstituição (healing) em } \\
\text { todos os níveis (físico e } \\
\text { não-físico), ambiente sutil } \\
\text { de energia e consciência, no } \\
\text { qual a totalidade, beleza, } \\
\text { conforto, dignidade e paz } \\
\text { sejam potencializadas. }\end{array}$ & $\begin{array}{l}\text { - Criar um ambiente confortável; } \\
\text { - Reconhecer as fragilidades do ser } \\
\text { cuidado; } \\
\text { - Ter consciência de quando tocar o } \\
\text { corpo está atingindo não só o físico, } \\
\text { mas o espiritual e íntimo do cliente. } \\
\text { - Estimular mudanças de decúbito. }\end{array}$ \\
\hline
\end{tabular}




\begin{tabular}{|c|c|c|}
\hline $\begin{array}{l}\text { Diagnósticos de } \\
\text { Enfermagem }\end{array}$ & $\begin{array}{l}\text { Elementos do Processo } \\
\text { Clinical Caritas }\end{array}$ & Manifestações de Cuidado \\
\hline $\begin{array}{l}\text { Risco de religiosidade } \\
\text { prejudicada } \\
\text { relacionado a } \\
\text { insegurança quanto } \\
\text { a morte, apoio } \\
\text { familiar insuficiente } \\
\text { e interações } \\
\text { socioculturais } \\
\text { ineficazes }\end{array}$ & $\begin{array}{l}\text { - Dar abertura e atender } \\
\text { aos mistérios espirituais e } \\
\text { dimensões existenciais da } \\
\text { vida-morte, cuidar da sua } \\
\text { própria alma e da do ser } \\
\text { cuidado; } \\
\text { - Cultivar práticas espirituais } \\
\text { próprias e do eu transpessoal } \\
\text { e ir além do próprio ego. }\end{array}$ & $\begin{array}{l}\text { - Estimular práticas religiosas } \\
\text { próprias culturais. } \\
\text { - Conhecer e compreender } \\
\text { verdadeiramente os valores e } \\
\text { crenças religiosas e orientar de } \\
\text { acordo com o significado do cuidado } \\
\text { ao indivíduo. } \\
\text { - Transcender o conhecimento } \\
\text { cientifico, engajando-se na crença de } \\
\text { cura pela religiosidade. } \\
\text { - Incentivar ao paciente a busca } \\
\text { pela força interior no processo de } \\
\text { bem-estar em todos os âmbitos do } \\
\text { indivíduo mente-corpo-espírito. }\end{array}$ \\
\hline
\end{tabular}

Fonte: elaborado pelos autores (2019), conforme proposto por WATSON (2012) e TONIN et al., 2017.

Tais resultados são possíveis mediante a análise do quadro clínico e compreensão de quais áreas ou especificidades do paciente precisam ser atendidas e trabalhadas, correlacionando-as com seu estado geral e o uso de referencial teórico. Durante a busca dos resultados ficou evidente a necessidade de uma equipe multidisciplinar para a continuidade do cuidado, mesmo que baseado em uma teoria de Enfermagem.

\section{DISCUSSÃO}

O modelo de formação do enfermeiro no Brasil é orientado pelas Diretrizes Curriculares Nacionais (BRASIL, 2001), a partir da qual almeja-se o perfil do formando, quando egresso/profissional, deverá ser o de enfermeiro com formação generalista, humanista, crítica e reflexiva. O profissional deve estar qualificado para o exercício da enfermagem com base no rigor científico e intelectual e pautado em princípios éticos, sendo capaz de conhecer e intervir sobre os problemas ou situações de saúde-doença mais prevalentes no perfil epidemiológico nacional, com ênfase à região de atuação, identificando as dimensões biopsicossociais de seus determinantes. Consequentemente, o enfermeiro deve estar capacitado para atuar com responsabilidade social e compromisso com a cidadania, promovendo a saúde integral dos seres humanos (DCN, 2001).

Nesse cenário, ainda é possível perceber lacunas na formação dos enfermeiros, o que tem levado esses profissionais a aplicarem o processo de enfermagem com forte influência do modelo biomédico, centrado exclusivamente nas alterações patológicas, dando-se pouca ênfase aos aspectos humanísticos e à espiritualidade dos seres que são cuidados (REIGEL, CROSSETTI, SIQUEIRA, 2018). 
No entanto, não se pode deixar de considerar que algumas Instituições de Ensino Superior no Brasil têm buscado romper com esse paradigma da formação, incluindo em seus currículos disciplinas capazes de dar conta das demandas sociais emergentes à formação dos enfermeiros. A Teoria do Cuidado Humano de Jean Watson como referencial teórico-metodológico proporcionou desenvolver o cuidado profissional humanizado, a qual transcende o manejo do paciente comprometido à sua comorbidade e vislumbra o ser humano como um todo, respeitando além de suas limitações, suas vontades e crenças num cuidado holístico do ser.

Acredita-se que esta forma de ciência é coerente com o contexto paradigmático, proporciona evolução dos fenômenos disciplinares da enfermagem, por incluir todas as vicissitudes da existência humana - a imanência e transcendência, permitindo assim, uma aliança sagrada: humano-a humana; e humano para com o divino (WATSON, 2018).

$\mathrm{Na}$ experiência relatada, o paciente encontrava-se em cuidados paliativos, diagnosticado com DPOC internado em uma UTI. Trata-se, de uma situação complexa à equipe de enfermagem, uma vez que diversos fatores interferem na realização do cuidado, dentre eles: o paciente, o ambiente, a dinâmica desta unidade intensiva e os profissionais envolvidos nos cuidados.

Para Rabelo, Souza e Silva (2017) o paciente que encontra-se no âmbito de uma UTI mostra-se fragilizado em diferentes contextos que envolvem todas as esferas do cuidado (físico, psicológico, social, espiritual), assim a elaboração de modelos aplicáveis, a partir dos Elementos do Processo Clinical Caritas, que abrangem os pacientes nestas circunstâncias facilitam aos profissionais da Enfermagem fundamentar o cuidado a teoria, podendo alcançar a transpessoalidade do cuidado.

Na literatura, observa-se a aplicação da Teoria do Cuidado Humano em diversas instituições de saúde, com melhora na qualidade do cuidado prestado e com satisfação para quem realiza (DURANT, 2015; SWENGOS, 2014; EMOTO, 2015, TONIN et al., 2019).

Desta forma, entende-se que a aplicação da Teoria do Cuidado Humano, pode envolver práticas e cuidados relacionados aos diagnósticos de enfermagem, para que todas as necessidades do paciente consigam ser supridas e o cuidado consiga ser holístico. Entretanto, a fim de otimizar o cuidado ao paciente é importante que este seja realizado por uma equipe multidisciplinar onde cada profissional possa contribuir com a sua assistência ao paciente (SAVIETO e LEÃO, 2016). Além disso, o guia para a realização dos elementos do Processo Clinical Caritas (TONIN et al., 2017), demonstrou ser facilitador, tanto para o ensino dos pressupostos desta teoria, como para identificar as manifestações de cuidado necessárias para o alcance dos objetivos.

Em relação aos diagnósticos de enfermagem que teve maior predominância para o caso, foram de conforto prejudicado e dor crônica com 
base no North American Nursing Diagnosis Association (2017). Para a realização dos cuidados a partir destes diagnósticos, utilizou-se elementos do Processo Clinical Caritas, como já citado. Assim, é válido ressaltar que algumas ações se demonstraram mais relevantes para o alcance dos objetivos como: empatia, permitir-se ao cuidado humanizado na relação profissional - paciente, analisar, ponderar a situação, particularizar cada paciente, não julgar nem comparar um paciente com outro e principalmente respeitar a vida na sua fragilidade.

A abordagem do profissional de enfermagem por vezes pode ser equivocada, uma vez que existem diversos fatores durante o dia a dia desses profissionais que fazem com que não recepcionem o paciente da forma como deveria, por isso é tão difícil implementar na prática as ações que Jean Watson preza (JONES, 2018).

Todavia, algumas mudanças no cotidiano do enfermeiro podem contribuir para que se torne um profissional mais atento em relação ao cuidado transpessoal, como sendo: a carga horária de trabalho, a quantidade de pacientes destinados ao seu cuidado, outros empregos e até mesmo a educação que esse profissional teve e como sua mente se moldou (FAVERO et al., 2009).

Portanto, a enfermagem ao optar pelo cuidado transpessoal pode ter como resultado a satisfação do paciente, bem como, afetar o ser e o estar e os que estão a sua volta. Embora existam grandes dificuldades para se buscar esse cuidado transpessoal, de corpo e alma, a enfermagem pode buscar algum tipo de melhoria e que essa prática seja concretizada com uma educação continuada de período em período, a ponto de ser uma prática rotineira e habitual (JONES, 2018).

Segundo Savieto e Leão (2016) para a busca pela empatia que a teorista Jean Watson estima no nosso cotidiano, é imprescindível a compreensão da experiência em que o paciente está vivendo. Para tanto, é necessário estar integralmente presente no momento do cuidado ao paciente e devem ser esquecidas questões que não dizem respeito à vida do mesmo, para que o cuidado holístico e a empatia esperada, consigam ser conquistadas. Sendo assim, podemos realizar um cuidado humano com o paciente até mesmo ao realizar procedimentos práticos, e desta forma iremos adquirir ensinamentos que nos façam se colocar no lugar do outro (SAVIETO; LEÂO, 2016).

Nesse sentido, identifica-se a importância das bases teóricas e filosóficas da profissão de enfermagem enquanto ciência e arte, as quais devem permear os fundamentos da formação dos enfermeiros, que devem conhecer e aplicar em sua prática profissional as teorias e a filosofia da enfermagem, temas importantes que dão os subsídios necessários ao processo de enfermagem em todas as suas etapas, com qualidade e segurança ao paciente (REIGEL, CROSSETTI, SIQUEIRA, 2018).

Presume-se que os estudantes ao vivenciarem esta experiência durante a sua formação e enfermeiros que conhecem a Teoria do Cuidado Humano de 
Watson (e que a aplicam em suas práticas) podem qualificar e desenvolver o pensamento crítico em uma perspectiva holística. De modo a refletir diretamente no processo de cuidar em diferentes contextos de formação/ensino, assistência e pesquisa (ACKERMAN, 2018). Dessa forma, os espaços de cuidado e ensino tornam-se mais humanos, éticos, estéticos e solidários.

\section{CONSIDERAÇÕES FINAIS}

A partir da aplicação prática da Teoria do Cuidado Humano de Jean Watson, foi possível identificar e correlacionar situações vividas com a aplicação dos Elementos do Processo Clinical Caritas, e assim, constatar o quão importante é o papel do enfermeiro neste processo de saúde e doença, e/ou finitude da vida.

Logo pode-se perceber que todo cuidado deve almejar o máximo de benefícios e conforto ao paciente e familiares, principalmente a plenitude entre profissional e o ser cuidado, este que se encontra vulnerável, e o profissional deve estar no seu momento de entrega total para que este cuidado aconteça de forma integral e genuína; para que se caracteriza uma prática de amorreconstituição e de transcendência pessoal, deve-se abranger todas as necessidades do ser humano nos contextos psicossociais, físicos e espirituais.

E assim, o cuidado transpessoal proporciona ao enfermeiro ou ao futuro profissional, acolher, confortar, orientar, respeitar e ofertar ao paciente um cuidado digno e responsivo as suas necessidades de saúde. Entretanto, o estudo limita-se a uma perspectiva de um fenômeno específico, de uma aplicação da realidade em um único serviço, devendo-se considerar a limitação espacial e temporal.

Assim, sugerem-se pesquisas que incluam a perspectiva do paciente ao cuidado transpessoal desenvolvido, bem como a inclusão de diferentes populações e estratégias de preparo para os profissionais enfrentarem as adversidades evitando que o cuidado profissional desenvolvido se limite a uma transposição simplista de uma assistência intervencionista.

\section{REFERÊNCIAS}

ACKERMAN,Linda. Caring Science Education: Measuring nurses caring behaviors. 2018.

ARSLAN-OZKAN, Ikay.; OKUMUS, Hulya.; BULDUKOGLU, Kadriye. A randomized controlled trial of the effects of nursing care based on Watson's Theory of Human Caring on distress, self-efficacy and adjustment in infertile women. Journal of Advanced Nurse, Turquia, v.70, n. 8, p.1801-1812, 2014. Disponível em: <https:// onlinelibrary.wiley.com/doi/epdf/10.1111/jan.12338>. Acesso em: 13 jan.2019.

BRASIL. Resolução CNE/CES n ${ }^{\circ}$, de 7 de novembro de 2001: Institui as Diretrizes Curriculares Nacionais do Curso de Graduação em Enfermagem, 2001. Disponível 
em: <http://www.portalmec.gov.br/cne/arquivos/pdf/ces03.pdf>. Acesso em: 18 jan.2018.

DURANT, Anne Fross et al. Caring Science: Transforming the Ethic of Caring-Healing Practice, Environment, and Culture within an Integrated Care Delivery System. Perm. J. Fall, Estados Unidos, v.19, n. 4, p.136-142, 2015. Disponível em:<https:/ / www. thepermanentejournal.org/files/Fall2015/NursingResearch.pdf>. Acesso em: 15 jan.2019.

DYNIEWICZ, Ana Maria. Metodologia da pesquisa em saúde para iniciantes. 1.ed. São Paulo: Difusão, 2009.

EMOTO, Rina; TSUTSUI, Mayumi; KAWANA, Ruri. A Model to Create a Caring and Healing Environment for Nurses in Child and Family Nursing. International Journal for Human Caring. International Journal for a Human Caring, v.19, n. 1, p.8-12, 2015.

JONES, Shannon N. Watson's Theory of Human Caring: Effect on Nurse Perception of Care Environment. 2018, Tese de Doutorado, Gardner-Webb University. 2018.

MACHADO, Eidiane R.; SOARES, Narciso V. Humanização em UTI: Sentidos e significados sob a ótica da equipe de saúde. R. Enferm. Cent. O. Min., vol.6, n.3, p.2342-2348, 2016. Disponível em: <http:/ / seer.ufsj.edu.br/index.php/recom/article/ view/1011/1167>. Acesso em: 11 jan.2019.

MEDEIROS, Jorge R.O. La humanización de los cuidados de enfermería intensiva: la posición de las enfermeras de UCI frente al aspecto humano del cuidado intensivo. 2017, 32f. Dissertação (Graduação - Enfermagem) - Setor de Medicina, Enfermagem e Fisioterapia, Universidad de La Laguna, Tenerife, 2017. Disponível em: <https:/ / riull.ull.es/xmlui/bitstream/handle/915/5357/La\%20humanizacion\%20de\%20 los $\% 20$ cuidados $\% 20$ de $\% 20$ enfermeria $\% 20$ intensiva $\% 20 l a \% 20$ posicion $\% 20 \mathrm{de} \% 20$ las $\% 20$ enfermeras $\% 20 \mathrm{de} \% 20 \mathrm{UCI} \% 20$ frente $\% 20$ al $\% 20$ aspecto $\% 20$ humano $\% 20 \mathrm{del} \% 20$ cuidado\%20intensivo.pdf?sequence=1>. Acesso em: 20 out.2018.

MELLO, Carolina C.V.; ALVES, Rodrigo O.; LEMOS, Stela M.A. Metodologias de ensino e formação na área da saúde: revisão de literatura. Rev. CEFAC, São Paulo, v. 16, n. 6, p. 2015-2028, 2014. Disponível em: <http:/ / www.scielo.br/scielo. php?script=sci_arttext\&pid=S1516-18462014000602015\&lng=en\&nrm=iso $>$. Access em: 07 fev.2019.

NANDA. Diagnósticos de enfermagem da Nanda. 10 ed. Artmed. Porto Alegre. 20152017.

ORGANIZAÇÃO MUNDIAL DA SAÚDE. Palliative Care Definition, 2015.

Disponível em: <https:/ /www.who.int/cancer/palliative/es/>. Acesso em: 20 out.2018.

OGRADOWSKI, Karin R.P. et al. Uso da metodologia da problematização e ensino da bioética: aprendizagem ativa e significativa. In: RAULI, Patricia M.F. et al. (organizadores). Bioética e Metodologias ativas no ensino-aprendizagem. Série Bioética. Volume 7. Editora CRV: Curitiba, 2018. 
RABELO, Ana C. S.; SOUZA, Fabíola V. F. S.; SILVA, Lúcia F. Contribuição do cuidado transpessoal ao ser-cardiopata no pós-operatório de cirurgia cardíaca. Revista Gaúcha de Enfermagem, Rio Grande do Sul, v. 38, n. 4, p. 1-10, 2017. Disponível em: <http:/ / www.scielo.br/pdf/rgenf/v38n4/1983-1447-rgenf-38-04-e64743.pdf >. Acesso em: 20 jan.2019.

RIEGEL, Fernando; CROSSETI, Maria da Graça O.; SIQUEIRA, Diego S. Contribuições da teoria de Jean Watson ao pensamento crítico holístico do enfermeiro. Rev. Bra. de Enf., Brasil, v. 71, n. 4, 2018. Disponível em: <http:/ /www.scielo.br/pdf/reben/ v71n4/pt_0034-7167-reben-71-04-2072.pdf>. Acesso em: 20 jan.2019.

SAVIETO, Roberta M; LEÃO, Eliseth L. Nursing assistance and Jean Watson: a reflection on empathy. Rev. Esc. Anna Nery, v. 20, n. 1, p.198-202, 2016. Disponível em: <http:/ / www.redalyc.org/html/1277/127744318026/>. Acesso em 20.jan.2019.

SEIXAS, Mariana B.; RICARDO, Djalma R.; RAMOS, Plínio S. Reabilitação domiciliar com exercício não supervisionado na DPOC: revisão sistemática. Rev. Bras. Med. Esporte, São Paulo, v. 22, n. 4, p.320-345, 2016. Disponível em: <http:/ / www.scielo. br/scielo.php?pid=S1517-86922016000400320\&script=sci_abstract\&tlng=pt $>$. Acesso em: 20 out.2018.

SWENGROSS, Diane et al. Promoting caring-healing relationships: bringing healing touch to the bedside in a multihospital health system. Holist Nurs Pract, Estados Unidos, v. 28, n. 6, p.3070-375, 2014. Disponível em: <https:/ / www.ncbi.nlm.nih.gov / pubmed/25314110>. Acesso em 12 jan.2019.

TONIN, Luana et al. Guia para a realização dos elementos do Processo Clinical Caritas. Rev. Esc. Anna Nery, v. 21, n. 4, p. 1-7, 2017. Disponível em: <http:/ /www. scielo.br/pdf/ean/v21n4/pt_1414-8145-ean-2177-9465-EAN-2017-0034.pdf>. Acesso em 20 out.2018.

TONIN, Luana et al. Transpersonal caring model in home-Care nursing for children with special care needs. Journal of Nursing Education and Practice, v. 9, n. 1, p.105112. 2019. Disponível em: <http://www.sciedu.ca/journal/index.php/jnep/article/ view/13652/8766>. Acesso em: 20 jan.2019.

VIEIRA, Marta N.M.C.; PANUNCIO-PINTO, Maria P. A Metodologia da Problematização (MP) como estratégia de integração ensino-serviço em cursos de graduação na área da saúde. Rev. Med. Ribeirão Preto, São Paulo, v. 48, n. 3, p.241248, 2015. Disponível em: <http:/ / www.revistas.usp.br/rmrp/article/view/104310>. Acesso em 20 out.2018.

WATSON, Jean. Human caring science: a theory of nursing. 2.ed. Sudbury: Jones \& Bartlett Learning; 2012.

WATSON, Jean. Unitary Caring science as sacred science: Social/Sacred Action Research. Japanese Journal of Nursing Research, Japão, v. 51, n. 4, p.344-348, 2019. 